\title{
TRAFFIC MICROSCOPIC SIMULATION IN THE TOWN KYJOV
}

\author{
Gabriela Tylová, Kateřina Víchová
}

\begin{abstract}
The paper deals with the microscopic simulation in the selected town - Kyjov. Firstly, there is discussed a short literature review about traffic simulation. Secondly, there is an introduced methodology. For this paper was used the simulation software PTV Vissim. This software is mainly for the microscopic simulation. The next part is presented results from the selected intersection in the town Kyjov. Finally, there is simulated construction of the new logistics centre and the impact of the traffic on the chosen intersection in the city.
\end{abstract}

Keywords: PTV Vissim, simulation, model, intersection, traffic

\section{INTRODUCTION}

Transport infrastructure is influenced by historical, political, cultural, structural, and economic aspects of urban development. In modern conditions, traffic intensity and transport composition undergo significant changes. Traffic intensity is noted as the first and primary determinant of traffic safety. (Volkova \& Stepanenko, 2019)

This paper deals with simulation in software PTV Vissim. The aim of the paper is to simulate the intersection and traffic situation, which will be created by the construction of a logistics centre, but mainly to illustrate the traffic situation at the intersection in the town of Kyjov and approach simulation creation in PTV Vissim. I chose this intersection because it is one of the busiest intersections in Kyjov. The simulation is based on the map of the intersection in Kyjov. The intersection is located in the centre of Kyjov in the Hodonín district in the South Moravian Region. Road I / 54 on which intersection on lead from Slavkov u Brna to Strani and further to Slovakia to Nove Mesto nad Vahom. Here cross Nerudova Street with Kollárova Street and Jiráskova Street. PTV Vissim is software for microscopic simulation of public transport, including, for example, cars and trucks, buses, cyclists, or pedestrians. It is mainly used in the assessment of transport infrastructure designs and traffic management on roads. The aim of the paper will be present the current state of the selected intersection and the impact for the traffic flow in the city.

\section{METHODOLOGY}

In this paper was used several methods. Firstly, there was used method of analysis, where we must analyse the current state of the traffic in the city. Secondly, there was used methods of modelling and simulation of traffic flow. Finally, for the simulation, where was used the simulation software PTV Vissim.

\subsection{Modelling and simulation of traffic flow}

Firstly, there was used modelling and simulation of traffic flow. Simulation is a method based on experimenting with a model of the real system under investigation to obtain information about the behaviour of such a policy (the "what happens if..." method). (Lipka, 2015; VSB, 2009a)

Simulation is an imitation of the behaviour of real system development over time. Simulation is used when designing new systems (if it is cheaper than prototyping); to determine system 
requirements (sizing for different types of loads, both computers and transport networks); for training in the use of existing systems (it can be expensive to be played with); to modifications of existing systems (the introduction of new rules, adding new capacities); when an analytical model cannot be found. (Lipka, 2015; VSB, 2009a)

Traffic modelling and simulation is primarily used in traffic engineering and traffic planning. The aim is to create a model of transport in a given territory that could be used to simulate prospective transport relations or to verify alternative designs and adjustments. Transport models can be used in the design of transport infrastructure (geometric and width layout of the communication network), public transport design (introduction of new lines, location of stops, etc.), or environmental impact assessment. (Volkova \& Stepanenko, 2019; Koglin, 2015; VSB, 2009a; Cools, Moons \& Wets, 2010)

The basis of the traffic models is for the given purposes to model faithfully the movements of vehicles and their interaction. However, it is not possible to create a single universal model that can be used to model all situations. The main criteria are the extent of the modelled network, the degree of approximation to the real state, and the display of detail. (Volkova \& Stepanenko, 2019; Koglin, 2015; VSB, 2009a; Cools, Moons \& Wets, 2010)

Nano and microsimulation tools dominate the representation of the real state. For significant network analysis, modelling with these tools is disproportionately demanding and unnecessarily detailed, so it is preferable to use a higher degree of generalization using macro-simulation tools. For large-scale networks, it is desirable to generalize some of the details, and so the socalled abstraction is regularly applied. Typical examples of such generalizations in macroscopic models are, for example, intersections. These are perceived only as nodes within these networks, without a more detailed influence of their arrangement. Conversely, in nano or microsimulation models, intersections can be modelled to the smallest detail. Microsimulation using validated data allows a better approximation to reality than macrosimulation, which in turn provides more reliable and realistic data in bulk and summarizing results such as intensity, density, or speed of traffic flows. (Volkova \& Stepanenko, 2019; Koglin, 2015; VSB, 2009a; Cools, Moons \& Wets, 2010)

Simulations are divided into static (time is not necessary, the model always behaves the same way), dynamic (the system evolves, some features may change), macroscopic (monitor only aggregate values, e.g. network flows), mesoscopic (monitor the behaviour of homogeneous groups of objects, e.g. motorway columns), microscopic (track individual entities, e.g. individual vehicles), nanoscopic (detailed monitor behaviour of entities, e.g. driver decisionmaking modelling). (Lipka, 2015; VSB, 2009a)

The principles of microscopic simulation consist of calculating the movement of individual vehicles based on interactions with other cars. These simulations are based on mathematical models that take into account all available parameters of the transport network, vehicles, or driver behaviour. Each vehicle entering the modelled system during the simulation is unique and assigned specific characteristics such as destination, vehicle type, and behaviour, speed, etc. Microscopic simulations are very hardware intensive in this respect. The main representatives of microscopic simulation tools include VISSIM, PARAMICS, or AIMSUN. (Lipka, 2015; VSB, 2009a; VSB, 2009b)

\subsection{PTV Vissim}

PTV VISSIM is a microscopic simulation tool developed by the German company PTV AG in cooperation with the Technical University of Karlsruhe. It is software for microscopic simulation of individual and public transport. Thanks to its high level of detail processing, it 
could accurately simulate both city traffic, including cyclists and pedestrians, as well as highway sections, including large grade-separated junctions. (AF CityPlan, 2017; VSB, 2009b)

The software is primarily designed for modelling multimodal traffic flows, including cars and trucks, buses, rail vehicles (trams, trains, high-speed), cyclists, and pedestrians (the essence of VISSIM is Wiedemann's "car-following" model). In Vissim, you could simulate not only car traffic but also interaction with pedestrians and cyclists. It combines traffic-engineering experience with the possibility of presentation in 3D animations. (AF CityPlan, 2017; VSB, 2009b)

Vissim is used to analyse networks of all sizes, from individual intersections to large metropolitan areas. In these transport networks, it could model all functional categories of roads from highways to purpose-built drives. Vissim's scope of application also includes public transport and routes for cyclists and pedestrians. The ability to define an unlimited number of vehicle types allows the user a full range of multimodal operations. Vehicle types include cars, trucks, buses, cyclists, wheelchairs, pedestrians, airplanes, etc. (AF CityPlan, 2017; VSB, 2009b)

VISSIM is frequently used to assess transport infrastructure designs, traffic management design, its analysis, and simulation of telematics benefits in traffic management, public transport simulation, etc. Highly detailed input of traffic network elements allows displaying very accurate and corresponding simulation when the user directly sees the modelled state on the screen. (AF CityPlan, 2017; VSB, 2009b)

\section{CASE STUDY}

The microscopic simulation will take place at a selected intersection in the city Kyjov, Czech Republic. Kyjov currently has more than 11 thousand inhabitants and is a natural administrative and social centre for the other 41 surrounding villages. It is located 40 kilometres southeast of Brno and 18 kilometres north of Hodonín. The small river Kyjovka, also called Stupava, flows through the town. (Město Kyjov, n.d.; Wikipedia, n.d.)

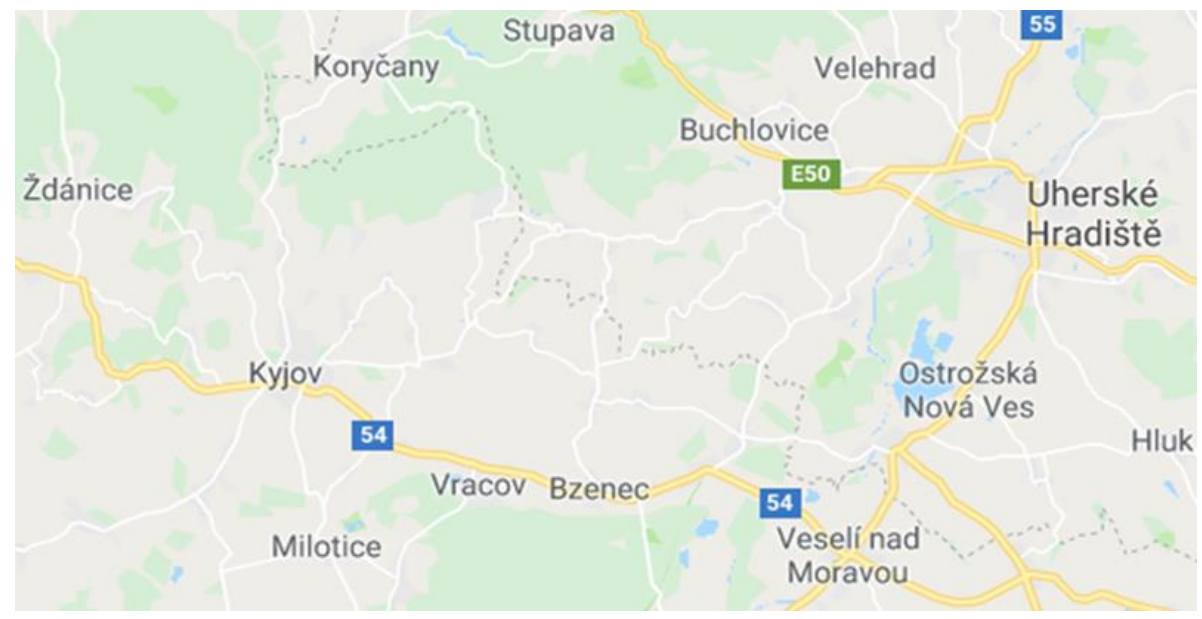

Fig. 1 - Town Kyjov in map. Source: Google Maps (n.d.)

The nearest surroundings of Kyjov have the character of deforested hills with fields, orchards, and vineyards. Only a few kilometres west and north of the city, however, are rising significantly higher, wooded peaks of the Věteřovská Highlands, Ždánický Forest, and the Chrriby Mountains. Kyjov is divided into four parts: the city and three formerly independent villages - Nětčice, Boršov, and Bohuslavice. (Město Kyjov, n.d.; Wikipedia, n.d.) 


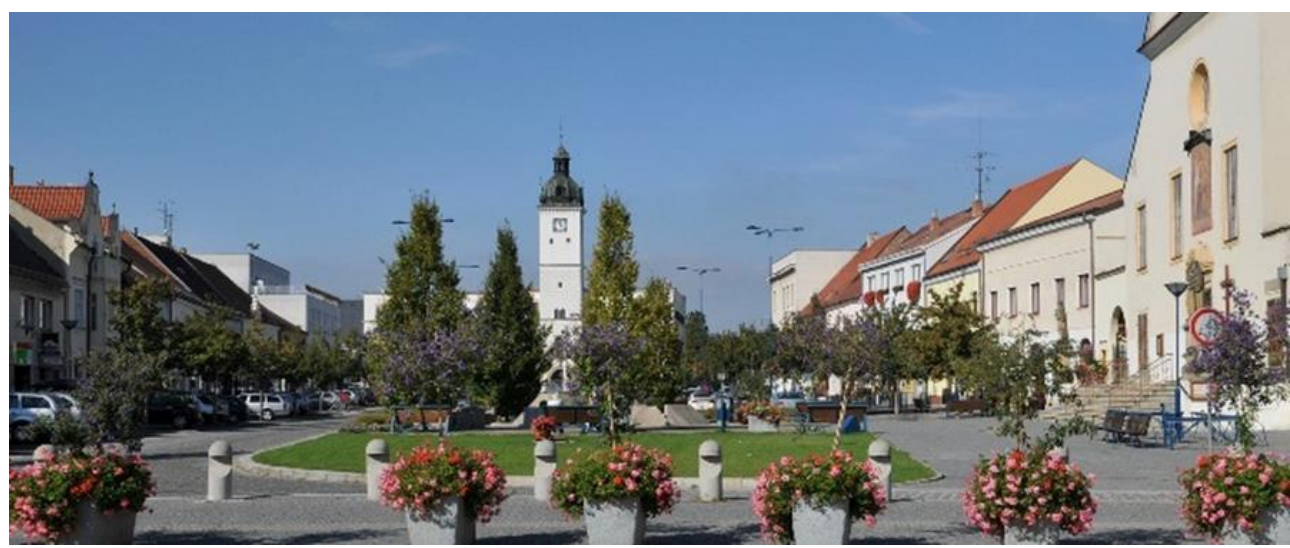

Fig. 2 - Main Square in Kyjov. Source: Město Kyjov (n.d.)

\subsection{Transport in the city}

The railway line No. 340, also called the Vlárská dráha (Railway), runs through the town from Brno to Uherské Hradiště. A railway line bypasses the city along its western and southern borders. The railway station building from 1887 was reconstructed in 2011 . The local part of Bohuslavice has its own railway station called Bohuslavice u Kyjova, and in the southern part of the town near the screw works, there is a railway stop. (Město Kyjov, n.d.; Wikipedia, n.d.)

The bus connection of Kyjov with the surrounding villages was gradually established during the First Republic. Since 1959 there has been a city bus service. Since 19 July 1976, a bus station on Nerudova Street has been in operation. Since 5 January 1998, the terminal has a terminal hall with a waiting room and bathroom. Due to the distance between the bus and train stations (about $1.2 \mathrm{~km}$ ), a transfer terminal was built at the train station in 2010. (Město Kyjov, n.d.; Wikipedia, n.d.)

Kyjov lies at the crossroads of roads I/54, II/432, and II/422. In 1965, an overpass over the railway line was built on the I/54 road in Kyjov, thus significantly simplifying the city transit. Since 1987, cars have been running along the bypass between the I/54 and II/432 roads in the western part of the city, thereby facilitating traffic in the centre. (Město Kyjov, n.d.; Wikipedia, n.d.)

On the road between Kyjov and Milotice, $3 \mathrm{~km}$ south of the city, was built in 1951 public domestic airport Kyjov with a grassy runway. It is operated by the civic association Aeroklub Kyjov. (Město Kyjov, n.d.; Wikipedia, n.d.)

\section{RESULTS}

The results contain several points, how was used the simulation software PTV Vissim. In the next part, there was final simulation of the current state of the selected intersection. Finally, there was added the building of the logistic centre and the impact for the traffic flow in the city.

\subsection{Current state}

For this paper was selected a specific intersection in Kyjov. The intersection is located in the centre of Kyjov in the Hodonín district in the South Moravian Region. Crossing the road (Nerudova Street) I / 54, leading from Slavkov u Brna to Strani and further to Slovakia to Nove Mesto nad Vahom. Here it crosses with a road passing through Kollárova Street connecting the city centre and Jiráskova Street ending at a screw shop. 


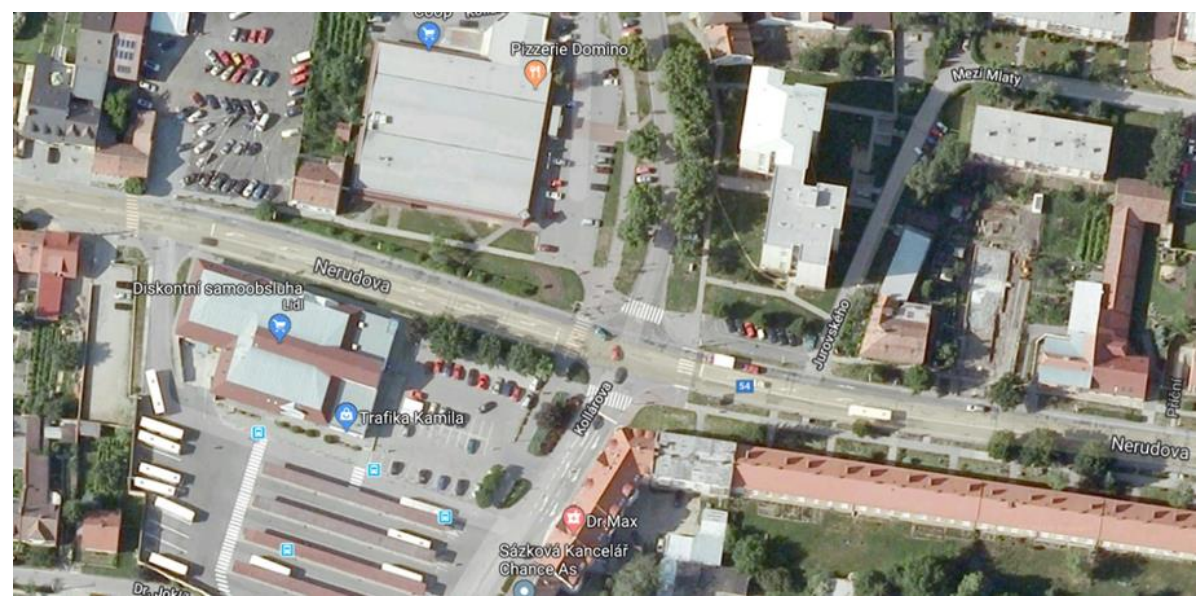

Fig. 3 - Aerial map of the intersection. Source: Google Maps (n.d.)

\subsection{Background images}

I made a map clipping and put it in the PTV Vissim. Next, I set a scale on 50 meters.

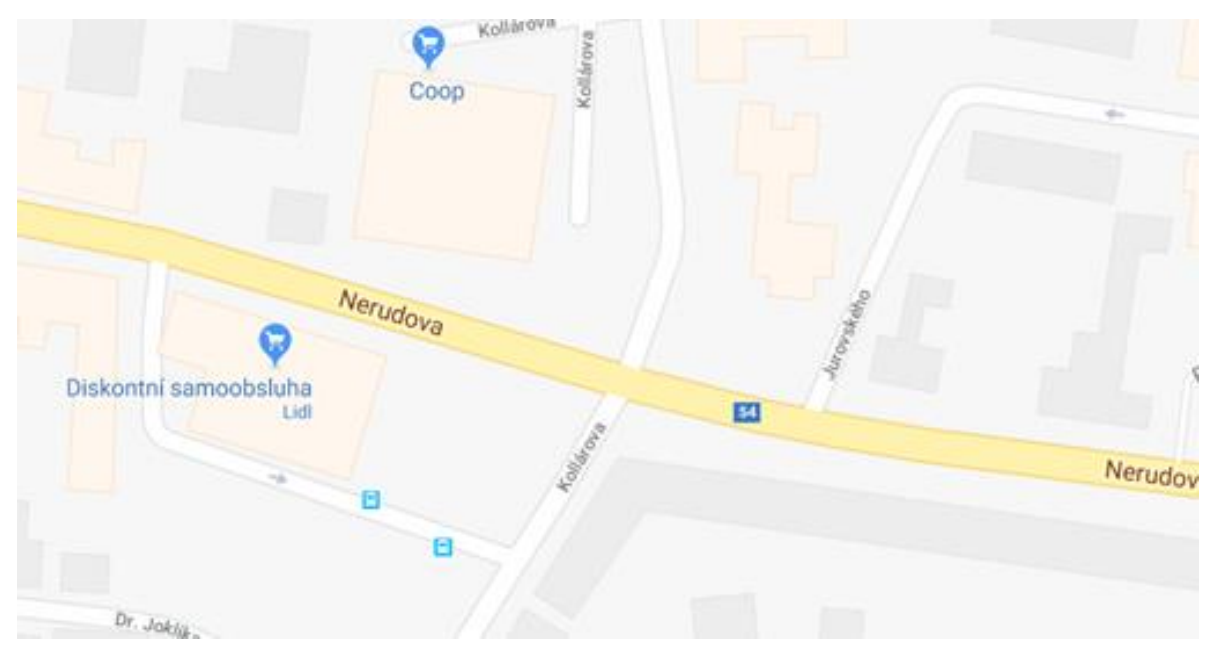

Fig. 4 - Aerial map of the intersection. Source: Google Maps (n.d.)

\subsection{Links, pavement markings}

A new road has been prepared in Jurovského Street, which will lead to a logistics centre. Subsequently, pedestrian crossings and road markings were added.

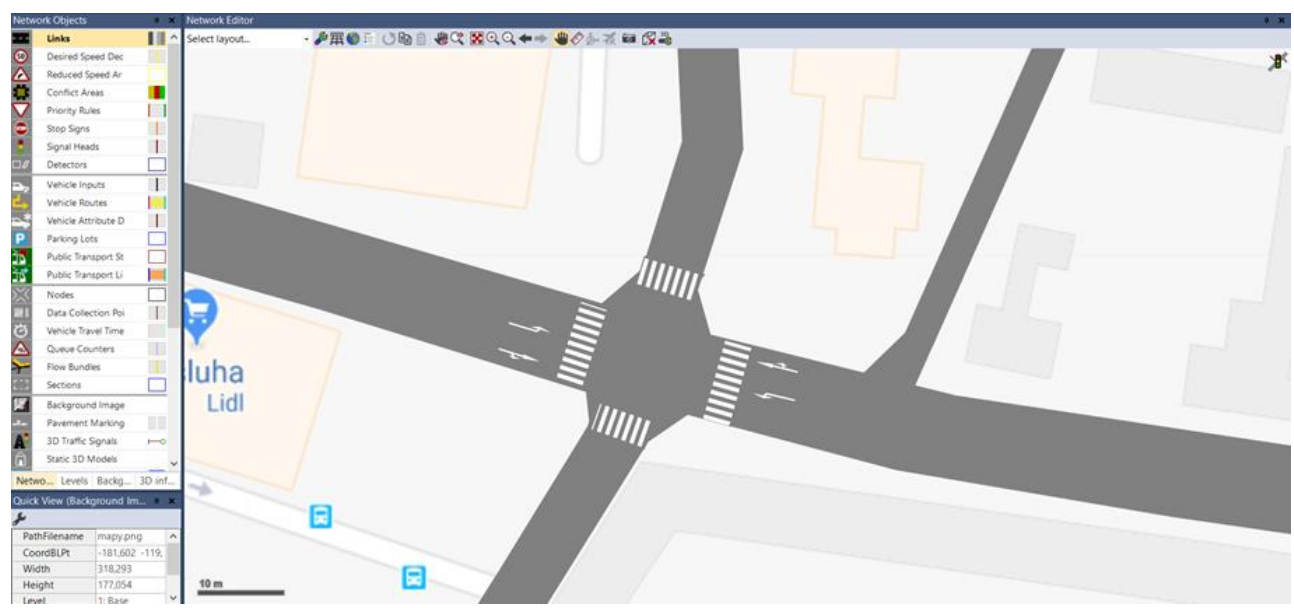

Fig. 5 - Links, pavement markings. Source: own research 


\subsection{Conflict areas, priority rules, signal heads}

Besides, conflict areas have been identified, which are where columns and priority rules are formed to indicate which car has priority over the road. Signal heads were then added. They are related to signal controllers, where you set the signal group and signal program, which determines how long each light shines on the traffic light.

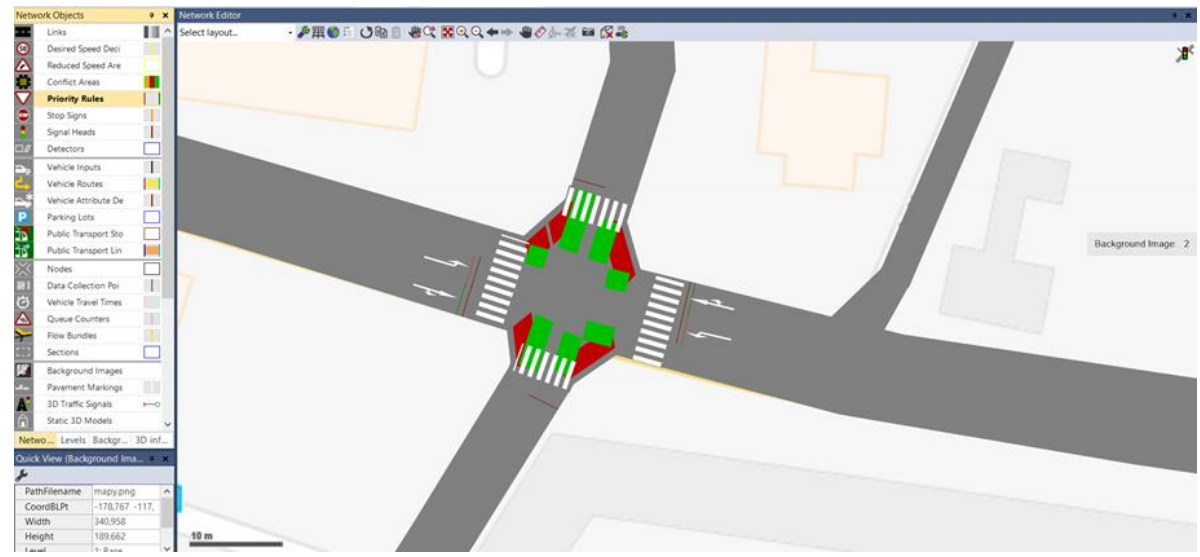

Fig. 6 - Conflict areas, priority rules, signal heads. Source: own research

\subsection{Vehicle inputs}

In the next step, I added vehicles and set up its volume.

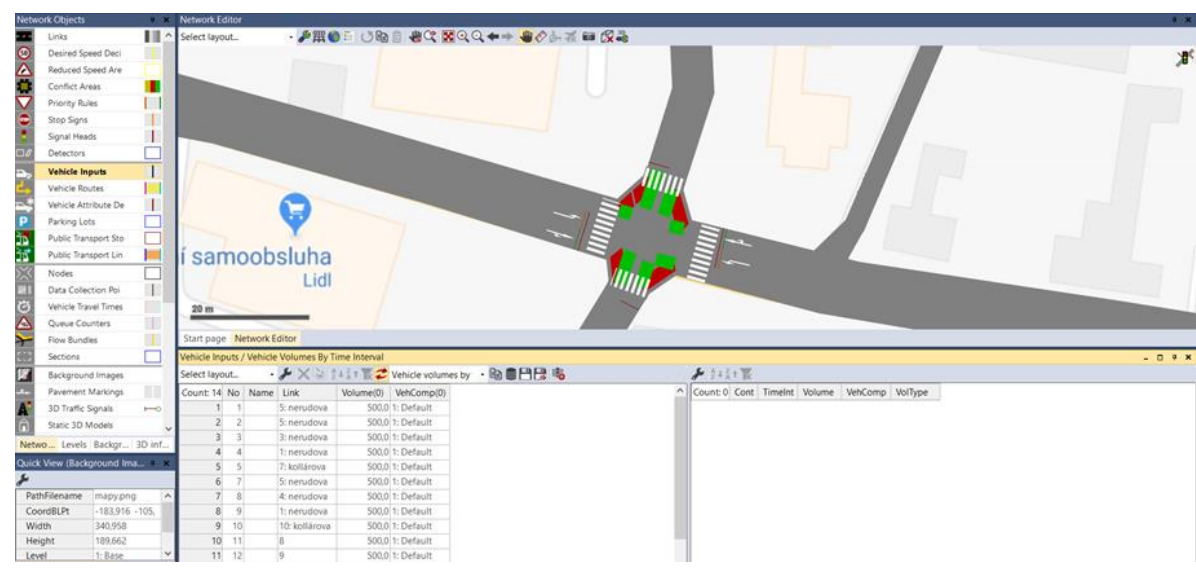

Fig. 7 - Setting up vehicles. Source: own research

\subsection{D simulation}

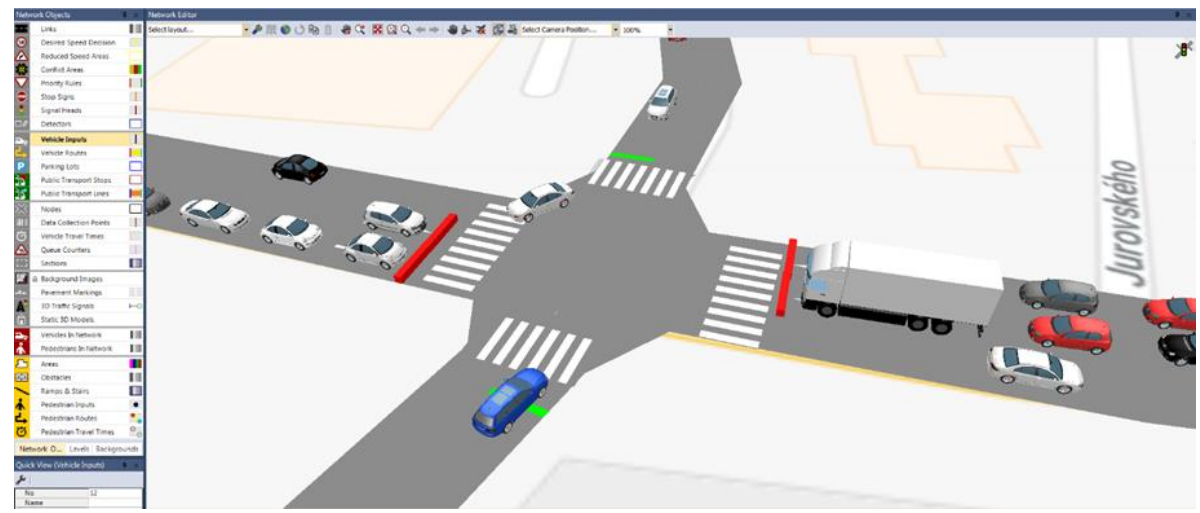

Fig. 8 - Intersection before construction of logistics centre. Source: own research 
Figure 8 shows the traffic situation looked like before the construction of the logistics centre, and figure 10, we could see how the traffic at the intersection changed after adding the road to the logistics centre.

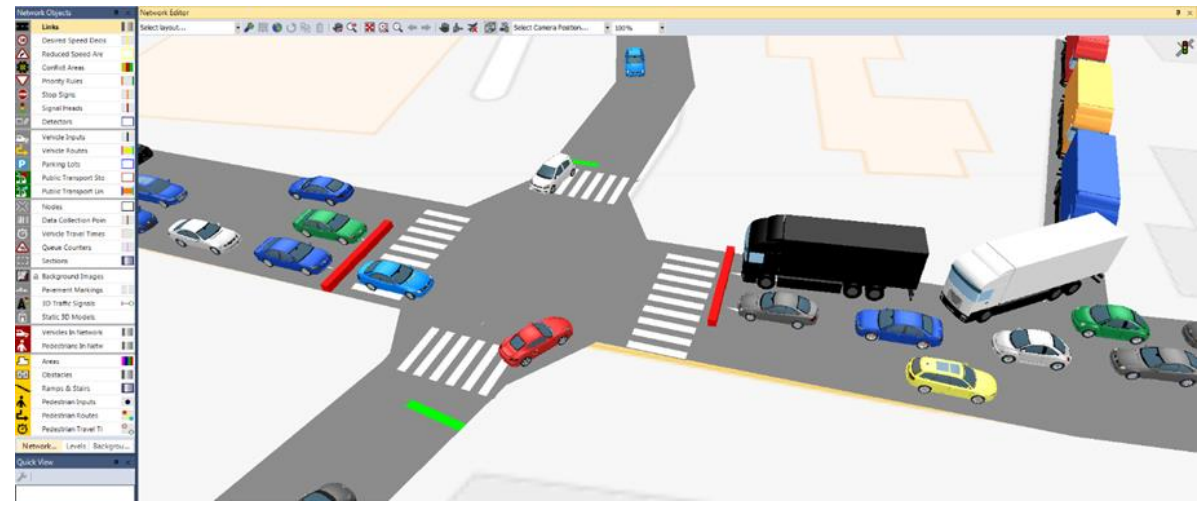

Fig. 9 - Intersection after construction of logistics centre. Source: own research

\subsection{Static 3D models, 3D traffic signals, signal controllers}

In the next step, static 3D objects, including buildings, benches, trees, and flowers, were added, and I created a car park. Then traffic lights for cars and pedestrians were added, and the signalling program was set up.

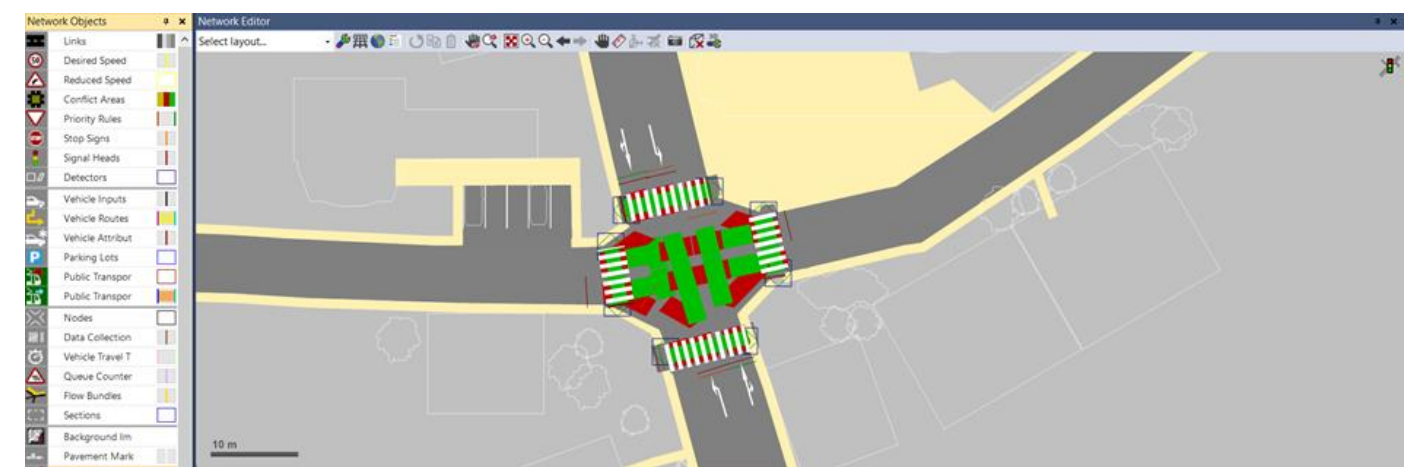

Fig. 10 - Static 3D models, 3D traffic signals, signal controllers. Source: own research

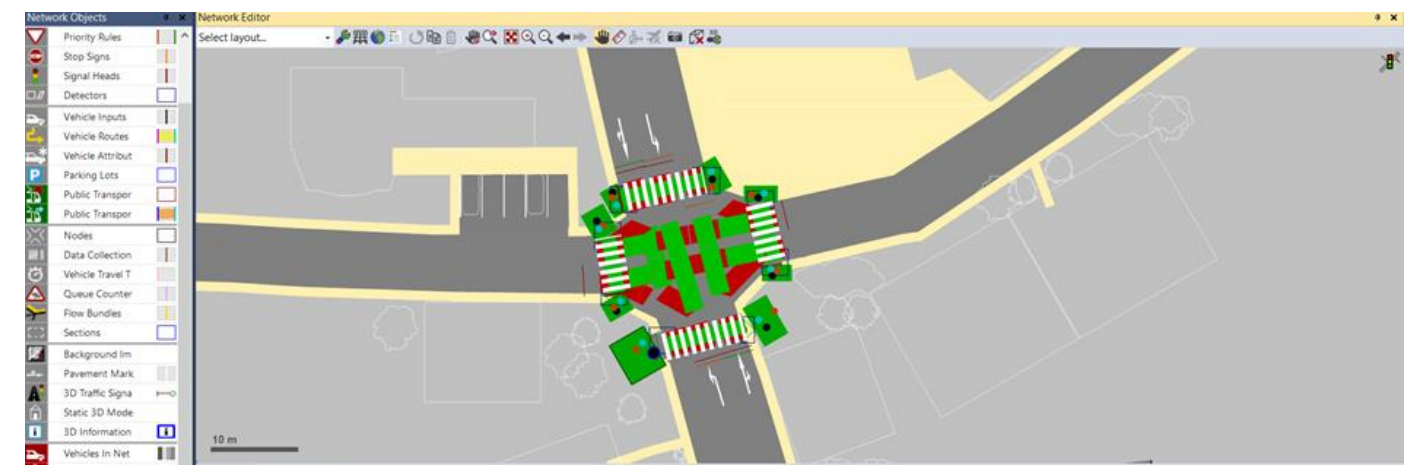

Fig. 11 - Pedestrian routes. Source: own research

\subsection{Final 3D simulation}

Figure 12 and 13 shows the results from the simulation software PTV Vissim. 


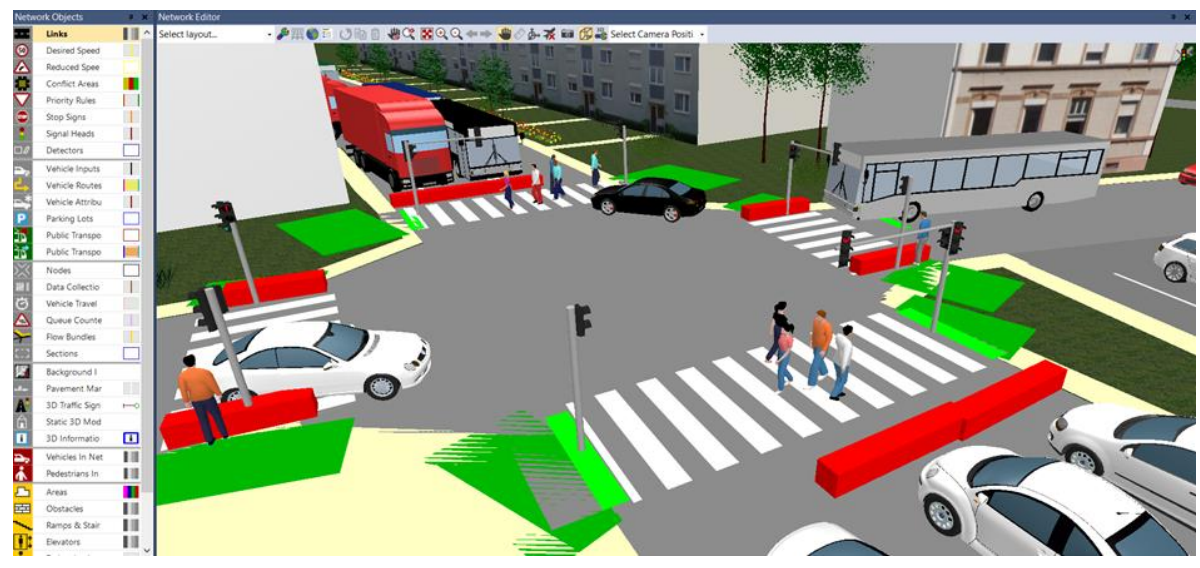

Fig. 12 - View of the intersection with pedestrians. Source: own research

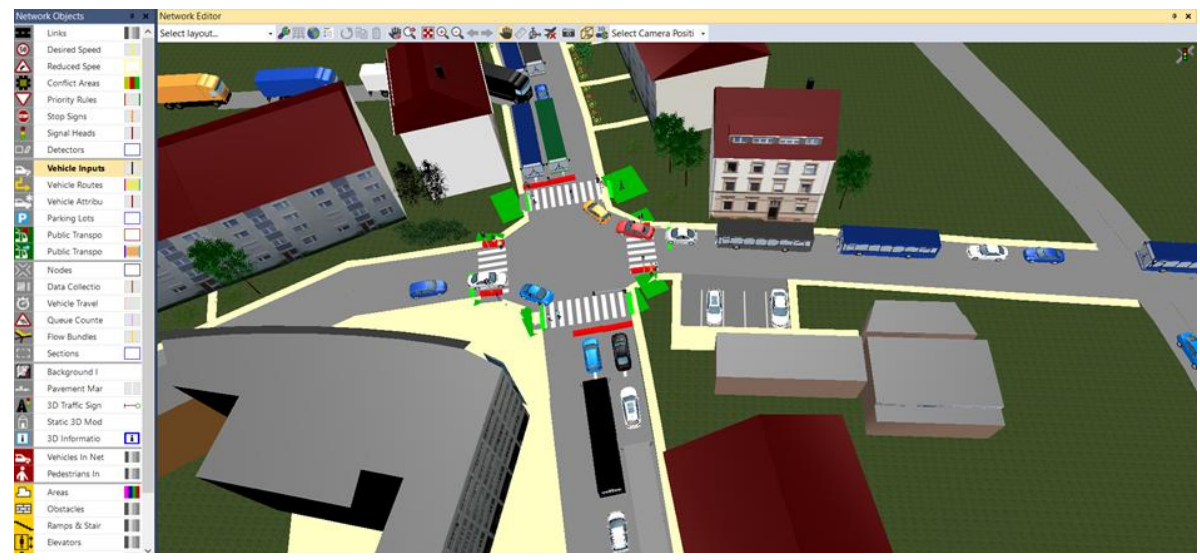

Fig. 13 - View of the intersection. Source: own research

\section{CONCLUSION}

The aim of the paper was to simulate the selected intersection in the city Kyjov and the traffic situation that would arise after the construction of the logistics centre. The simulation was presented based on the simulation software PTV Vissim. The first part involved the creation of a junction and a road leading to a logistics centre. Besides, the intersection was completed with other objects, including signalling equipment, 3D objects, and pedestrians. The thesis describes the simulation procedure and a demonstration of the new situation after the construction of the logistics centre. The simulation shows that trucks will significantly affect the case at the crossroads.

\section{References}

AF CityPlan (2017). PTV Vissim. Retrieved from http://www.af-cityplan.cz/vissim1404042539.html

Cools, M., Moons, E., \& Wets, G. (2010). Assessing the Impact of Weather on Traffic Intensity. Weather, Climate, and Society, 2(1), 60-68. doi: 10.1175/2009WCAS1014.1

Google Maps. (n.d.). Retrieved from https://www.google.com/maps

Koglin, T. (2015). Vélomobility and the Politics of Transport Planning. GeoJournal, 80, 569586. doi: 10.1007/s 10708-014-9565-7 
Lipka, R. (2015). Simulace systémů hromadné obsluhy. Retrieved from https://courseware.zcu.cz/CoursewarePortlets2/DownloadDokumentu?id=102129

Město Kyjov. (n.d.). Kyjov dnes. Retrieved from http://mestokyjov.cz/mesto-pro-zivot-anavraty/ds-1294/p1=2952

Volkova, E., \& Stepanenko, A. (2019). Traffic intensity on highway R-255 Siberia in Irkutsk region. IOP Conference Series Materials Science and Engineering, 667(1), 012107. doi: 10.1088/1757-899X/667/1/012107

VSB. (2009a). Kapitola IV. Modelování dopravy na pozemních komunikacích (ČÁST 1). Retrieved from http://projekt150.ha-vel.cz/node/94

VSB. (2009b). Kapitola IV. Modelování dopravy na pozemnich komunikacích (¿̌ÁST 3). Retrieved from http://projekt150.ha-vel.cz/node/96

Wikipedia. (n.d.). Kyjov. Retrieved from https://cs.wikipedia.org/wiki/Kyjov

\section{Contact information}

\section{Gabriela Tylová}

Tomas Bata University in Zlín, Faculty of Logistics and Crisis Management

Studentské náměstí 1532, 68601, Uherské Hradiště, Czech Republic

E-mail: g_tylova@utb.cz

ORCID: 0000-0001-8651-6590

\section{Kateřina Víchová}

Tomas Bata University in Zlín, Faculty of Logistics and Crisis Management

Studentské náměstí 1532, 68601, Uherské Hradiště, Czech Republic

E-mail: kvichova@utb.cz

ORCID: 0000-0003-3420-9411

doi: 10.7441/dokbat.2019.106 